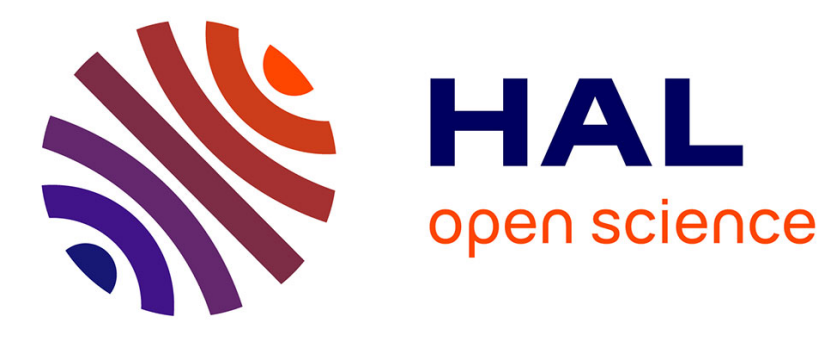

\title{
High-dose daptomycin in documented infections
}

\author{
Matteo Bassetti, Elena Nicco, Francesca Ginocchio, Filippo Ansaldi, Daniela \\ de Florentiis, Claudio Viscoli
}

\section{To cite this version:}

Matteo Bassetti, Elena Nicco, Francesca Ginocchio, Filippo Ansaldi, Daniela de Florentiis, et al.. High-dose daptomycin in documented infections. International Journal of Antimicrobial Agents, 2010, 36 (5), pp.459. 10.1016/j.ijantimicag.2010.07.011 . hal-00629956

\section{HAL Id: hal-00629956 https://hal.science/hal-00629956}

Submitted on 7 Oct 2011

HAL is a multi-disciplinary open access archive for the deposit and dissemination of scientific research documents, whether they are published or not. The documents may come from teaching and research institutions in France or abroad, or from public or private research centers.
L'archive ouverte pluridisciplinaire HAL, est destinée au dépôt et à la diffusion de documents scientifiques de niveau recherche, publiés ou non, émanant des établissements d'enseignement et de recherche français ou étrangers, des laboratoires publics ou privés. 


\section{Accepted Manuscript}

Title: High-dose daptomycin in documented Staphylococcus aureus infections

Authors: Matteo Bassetti, Elena Nicco, Francesca Ginocchio, Filippo Ansaldi, Daniela de Florentiis, Claudio Viscoli

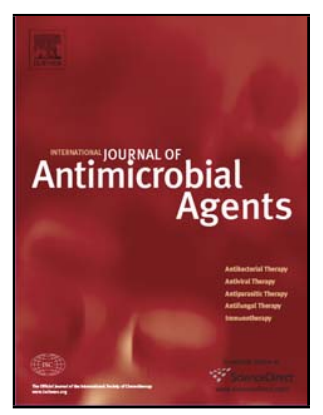

PII:

S0924-8579(10)00339-0

DOI: doi:10.1016/j.ijantimicag.2010.07.011

Reference: ANTAGE 3396

To appear in: International Journal of Antimicrobial Agents

Received date: $\quad 14-6-2010$

Revised date: $\quad 14-7-2010$

Accepted date: $\quad 16-7-2010$

Please cite this article as: Bassetti M, Nicco E, Ginocchio F, Ansaldi F, de Florentiis D, Viscoli C, High-dose daptomycin in documented Staphylococcus aureus infections, International Journal of Antimicrobial Agents (2010), doi:10.1016/j.ijantimicag.2010.07.011

This is a PDF file of an unedited manuscript that has been accepted for publication. As a service to our customers we are providing this early version of the manuscript. The manuscript will undergo copyediting, typesetting, and review of the resulting proof before it is published in its final form. Please note that during the production process errors may be discovered which could affect the content, and all legal disclaimers that apply to the journal pertain. 


\section{High-dose daptomycin in documented Staphylococcus aureus} infections

Matteo Bassetti ${ }^{a, *}$, Elena Nicco ${ }^{a}$, Francesca Ginocchio ${ }^{a}$, Filippo Ansaldi ${ }^{b}$, Daniela de Florentiis ${ }^{b}$, Claudio Viscoli ${ }^{a}$

${ }^{a}$ Infectious Diseases Division, San Martino Hospital and University of Genoa School of Medicine, Genoa, Italy

${ }^{\mathrm{b}}$ Hygiene Unit, San Martino Hospital and University of Genoa School of Medicine, Genoa, Italy

\section{ARTICLE INFO}

Article history:

Received 14 June 2010

Accepted 16 July 2010

Keywords:

Daptomycin

Staphylococcus aureus

Bacteraemia

High dose

CPK 
${ }^{*}$ Corresponding author. Present address: Clinica Malattie Infettive, A.O.U. San

Martino, Largo R. Benzi 10, 16132 Genova, Italy. Tel.: +39 010555 5132; fax: +39 0103537680.

E-mail address: matteo.bassetti@hsanmartino.it (M. Bassetti). 


\section{ABSTRACT}

Daptomycin is approved at a dose of $4-6 \mathrm{mg} / \mathrm{kg} /$ day for the treatment of complicated skin and soft-tissue infection and Staphylococcus aureus bloodstream infection.

Clinical experience with doses $>6 \mathrm{mg} / \mathrm{kg} /$ day is limited, but data reported to date suggest that daptomycin can be safe and effective at higher doses. We describe our experience with daptomycin at doses $>6 \mathrm{mg} / \mathrm{kg} /$ day and $\leq 6 \mathrm{mg} / \mathrm{kg} /$ day for $S$. aureus infections. A retrospective chart review of all patients treated with daptomycin from January 2008 to 28 February 2010 was performed. During the study period, 53 patients received daptomycin, including 22 patients receiving daptomycin at a standard dose (SD) (mean $5 \mathrm{mg} / \mathrm{kg} /$ day, range $4-6 \mathrm{mg} / \mathrm{kg} /$ day) and 31 patients receiving a higher dose (HD) (mean $8 \mathrm{mg} / \mathrm{kg} /$ day, range $7-9 \mathrm{mg} / \mathrm{kg}$ ). The median treatment duration was 13.5 days and 19 days for the SD and HD groups, respectively. Clinical success was observed in 16/22 patients (73\%) in the SD group and $29 / 31$ patients $(94 \%)$ in the HD group $(P=0.05)$. Microbiological success was observed in $13 / 19$ patients (68\%) and $27 / 29$ patients (93\%) in the SD and HD groups, respectively $(P<0.05)$. Of the 53 patients, $2 / 22$ treated with SD daptomycin and $3 / 31$ treated with HD daptomycin experienced a grade 1 adverse event while receiving therapy (i.e. anaemia, diarrhoea, nausea, hypokalaemia and arthralgia) but did not require discontinuation of daptomycin treatment. These results suggest that daptomycin may be used at doses higher than $6 \mathrm{mg} / \mathrm{kg} /$ day without toxicity and possibly with better outcome than conventional doses. We recommend further randomised controlled prospective studies with higher doses of daptomycin. 


\section{Introduction}

Daptomycin is a cyclic lipopeptide antibiotic with a unique mechanism of action against Gram-positive bacteria that provides potent and rapid bactericidal activity [1]. This bactericidal activity is concentration-dependent and its optimal expression may sometimes require levels equivalent to eight times the lipopeptide minimum inhibitory concentration (MIC) for a given strain [2]. Daptomycin is approved at a dose of 4 $\mathrm{mg} / \mathrm{kg}$ for the treatment of complicated skin and soft-tissue infection (cSSTI) and at a dose of $6 \mathrm{mg} / \mathrm{kg}$ for Staphylococcus aureus bloodstream infection (BSI), including treatment of right-sided endocarditis. Although prospective randomised clinical studies have claimed that these dosage regimens are safe and effective for their respective indications $[3,4]$, optimal doses level have not been firmly established. In recent years, reports of clinical failures and the emergence of resistant strains following daptomycin treatment have raised great concern $[5,6]$. As a result, higher doses of daptomycin are being proposed as an alternative for some difficult-to-treat infections such as complicated bacteraemia and endocarditis. Recently, doses of 10 $\mathrm{mg} / \mathrm{kg} /$ day were studied using an in vitro model of staphylococcal endocarditis, with promising results in terms of efficacy and prevention of resistance [7].

Pharmacokinetic data from healthy volunteers indicate that daptomycin, dosed once daily at $12 \mathrm{mg} / \mathrm{kg}$, achieved trough levels of ca. $20 \mu \mathrm{g} / \mathrm{mL}$, suggesting that this regimen might have sufficient activity against organisms with higher MICs [8]. Clinical experiences with doses $>6 \mathrm{mg} / \mathrm{kg}$ are limited, but data reported to date suggest that daptomycin appears to be safe and well tolerated even at higher doses [9-13]. A recent study of experimental foreign-body meticillin-resistant $S$. aureus infection suggested that high-dose daptomycin (10 mg/kg/day) ensured a profile of safety from 
the development of resistance [14]. In this article, we describe our experience with the clinical use of daptomycin at doses $>6 \mathrm{mg} / \mathrm{kg} /$ day and $\leq 6 \mathrm{mg} / \mathrm{kg} /$ day for documented S. aureus infections.

\section{Methods}

A retrospective chart review of patients treated with daptomycin for a minimum of 10 days at San Martino University Hospital (Genoa, Italy) from January 2008 to 28 February 2010 was conducted. The review was approved by the local institutional review board; patient consent was not required because of the observational nature of the study. Patients included in the analysis were divided in two groups, those who received daptomycin at doses $>6 \mathrm{mg} / \mathrm{kg} /$ day and those receiving $\leq 6 \mathrm{mg} / \mathrm{kg} /$ day in documented $S$. aureus infections. Clinical data were collected from medical records and included age, sex, co-morbid conditions, clinical diagnosis, microbiological isolate identification and antibiotic susceptibility, dose and duration of daptomycin treatment, adverse clinical events and creatine phosphokinase (CPK) levels. Susceptibilities of the isolates to daptomycin and vancomycin were determined by Etest (AB BIODISK, Solna, Sweden). Safety was determined using any adverse events documented in the medical record. Adverse events were graded 1-4 [15]. CPK levels were monitored after 7, 14 and >14 days in the two groups. Significant elevation in CPK level was defined as an increase in serum CPK value 10-fold greater than the upper limit of normal, with or without accompanying musculoskeletal symptoms. Daptomycin dosing was based on mg per kg of actual body weight. Infections were classified as uncomplicated BSI, complicated BSI, infective endocarditis, cSSTI and osteomyelitis. Definitions of uncomplicated BSI, complicated BSI and infective endocarditis were consistent with those used in published studies 
[3]. To assess the patient's overall clinical and microbiological response, the following categories were used: clinical success, defined as complete resolution of all signs and symptoms of infection; microbiological success, defined as eradication or presumed eradication of all baseline infecting pathogens and no isolation of superinfecting pathogens post therapy; clinical failure, defined as either no improvement or the need for other antibiotics to be added or substituted before improvement occurred; and microbiological failure, defined as the presence of a persisting pathogen or a superinfecting pathogen post therapy.

Comparisons of qualitative demographic, clinical and microbiological data as well as clinical and microbiological response rates between standard dose (SD) and higher dose (HD) groups were analysed by Fisher's exact test. Age, Acute Physiology and Chronic Health Evaluation (APACHE) II score, duration of hospitalisation and duration of therapy between SD and HD groups as well as CPK levels between different times and between the two treatment groups were compared by Wilcoxon and Kruskal-Wallis tests.

\section{Results}

During the study period, 53 patients received daptomycin for $S$. aureus infections, including 22 patients in the SD group receiving a mean of $5 \mathrm{mg} / \mathrm{kg} /$ day (range 4-6 $\mathrm{mg} / \mathrm{kg} /$ day) and 31 patients in the HD group receiving a mean of $8 \mathrm{mg} / \mathrm{kg} /$ day (range $7-9 \mathrm{mg} / \mathrm{kg}$ ). The characteristics of the patients are summarised in Table 1.

The two groups were comparable in terms of age, gender, underlying conditions, types of infection and type of $S$. aureus. Duration of hospitalisation [median 15 days 
(10-90th percentile 8.3-54.4 days) vs. 23 days (11-32 days)], APACHE II score [median 12 (10-90th percentile 7.3-22.4) vs. 16 (9-21.8)] and duration of therapy (median 13.5 days (10-90th percentile 10-51.3 days) vs. 19 days (14-52.2 days)] were higher in the HD group.

All of the S. aureus isolates were susceptible to daptomycin [MIC for $90 \%$ of the organisms $\left(\mathrm{MIC}_{90}\right)=0.5 \mu \mathrm{g} / \mathrm{mL}$, MIC range $\left.\leq 0.06-1 \mu \mathrm{g} / \mathrm{mL}\right)$. All patients included in the analysis received a minimum of 10 days of daptomycin treatment with a median of 16 days of treatment (range 10-92 days). All 53 patients underwent CPK analysis during treatment (maximum every 3 days). Clinical success was observed in 16/22 patients $(73 \%)$ in the SD group and $29 / 31$ patients $(94 \%)$ in the HD group $(P=0.05)$. Microbiological success was observed in 13/19 patients (68\%) and 27/29 patients $(93 \%)$ in the SD and HD groups, respectively $(P<0.05)$ (Table 2).

Of the 53 patients analysed, $2 / 22(9 \%)$ treated with SD and $3 / 31(9.7 \%)$ treated with HD experienced grade 1 adverse events while receiving therapy (i.e. anaemia, diarrhoea, nausea, hypokalaemia and arthralgia) but did not require discontinuation of daptomycin treatment. Differences in CPK levels were not observed either between different times or between the two treatment groups (Fig. 1). Only one patient (3.2\%) treated with HD experienced significant grade 3 CPK level elevation (levels $>1000 \mathrm{U} / \mathrm{L}$ ); daptomycin treatment was discontinued and CPK levels returned to normal within 1 week. 


\section{Discussion}

The appearance of clinical failures and resistant strains during daptomycin treatment has led to the suggestion that daptomycin might be used at higher doses for difficultto-treat infections $[5,6]$. In San Martino University Hospital, many physicians have started to use daptomycin at doses higher than recommended owing to this suggestion. The results of this experience suggest that daptomycin can be used at doses $>6 \mathrm{mg} / \mathrm{kg} / \mathrm{day}$ without significant toxicity and possibly with better outcome than conventional doses.

The clinical and microbiological success rates observed in this study with higher doses (mean dose $8 \mathrm{mg} / \mathrm{kg} /$ day) were superior to those observed with standard doses (mean dose of $5 \mathrm{mg} / \mathrm{kg} / \mathrm{day}$ ) and this observation may represent the rationale for planning randomised clinical trials comparing standard versus higher doses.

To date there are limited clinical data for the use of daptomycin at doses $>6 \mathrm{mg} / \mathrm{kg}$ [9-13]. In particular, there are no studies comparing the clinical and microbiological efficacies of higher doses with standard doses. In general, daptomycin is well tolerated, with few significant adverse events other than CPK level elevation. Clinical studies to date report an incidence of significant CPK level elevation of $2.1 \%$ with a dosage of $4 \mathrm{mg} / \mathrm{kg}$ in cSSTI and $8.3 \%$ with $6 \mathrm{mg} / \mathrm{kg}$ for up to 6 weeks in patients with S. aureus bacteraemia or endocarditis $[3,4]$. Two recent studies used higher doses ( $\geq 8 \mathrm{mg} / \mathrm{kg}$ ) of daptomycin for a variety of Gram-positive infections [12,13]. CPK level elevations occurred in $6-9 \%$ of patients treated with daptomycin, and discontinuation due to grade 3 adverse events occurred in $2.1 \%$ and $4.9 \%$, respectively [12,13]. A recent report of a pilot study on the treatment of CSSTI that used higher doses of 
daptomycin (10 mg/kg/day for 4 days) demonstrated an overall incidence of CPK level elevation of $8.3 \%$ [11]. The incidence of significant CPK elevations observed in this study (3.2\%) is similar to or lower than that reported by other authors using standard doses $[3,4,11-13]$.

There are several limitations to this study, including lack of randomisation, the small cohort of patients, its retrospective nature, variable types of infection and the longer duration of treatment in the HD group.

Our experience suggests that higher doses of daptomycin are safe and might be more effective than standard doses in $S$. aureus infections. This observation might represent the rationale for planning and conducting randomised clinical trials of higher versus standard dosing.

\section{Funding}

None.

\section{Competing interests}

MB has been a consultant to Novartis and a member of the speakers' bureau for Novartis. All other authors declare no competing interests.

\section{Ethical approval}

The review was approved by the Comitato Etico dell Azienda Ospedaliera Universitaria San Martino di Genova on October 2007; patient consent was not required because of the observational nature of the study. 


\section{References}

[1] DeRyke CA, Sutherland C, Zhang B, Nicolau D, Kuti JL. Serum bactericidal activities of high-dose daptomycin with and without co-administration of gentamicin against isolates of Staphylococcus aureus and Enterococcus species. Antimicrob Agents Chemother 2006;50:3529-34.

[2] Hanberger H, Nilsson LE, Maller R, Isaksson B. Pharmacodynamics of daptomycin and vancomycin on Enterococcus faecalis and Staphylococcus aureus demonstrated by studies of initial killing and postantibiotic effect and influence of $\mathrm{Ca}^{2+}$ and albumin on these drugs. Antimicrob Agents Chemother $1991 ; 35: 1710-6$.

[3] Arbeit RD, Maki D, Tally FP, Campanaro E, Eisenstein BI; Daptomycin 98-01 and 99-01 Investigators. The safety and efficacy of daptomycin for the treatment of complicated skin and skin-structure infections. Clin Infect Dis 2004;38:1673-81.

[4] Fowler VG Jr, Boucher HW, Corey R, Abrutyn E, Karchmer AW, Rupp ME, et al.; S. aureus Endocarditis and Bacteremia Study Group. Daptomycin versus standard therapy for bacteremia and endocarditis caused by Staphylococcus aureus. N Engl J Med 2006;355:653-65.

[5] Boucher HW, Sakoulas G. Perspectives on daptomycin resistance, with emphasis on resistance in Staphylococcus aureus. Clin Infect Dis 2007;45:601-8.

[6] Skiest DJ. Treatment failure resulting from resistance of Staphylococcus aureus to daptomycin. J Clin Microbiol 2006;44:655-6.

[7] Rose WE, Rybak MJ, Kaatz GW. Evaluation of daptomycin treatment of Staphylococcus aureus bacterial endocarditis: an in vitro and in vivo simulation using historical and current dosing strategies. J Antimicrob Chemother 2007;60:334-40. 
[8] Benvenuto M, Benziger DP, Yankelev S, Vigliani G. Pharmacokinetics and tolerability of daptomycin at doses up to 12 milligrams per kilogram of body weight once daily in healthy volunteers. Antimicrob Agents Chemother 2006;50:3245-9.

[9] Cunha BA, Eisenstein LE, Hamid NS. Pacemaker-induced Staphylococcus aureus mitral valve acute bacterial endocarditis complicated by persistent bacteremia from a coronary stent: cure with prolonged/high-dose daptomycin without toxicity. Heart Lung 2006;35:207-11.

[10] Cunha BA, Krol V, Kodali V. Methicillin-resistant Staphylococcus aureus (MRSA) mitral valve acute bacterial endocarditis (ABE) in a patient with Job' syndrome (hyperimmunoglobulin E syndrome) successfully treated with linezolid and high-dose daptomycin. Heart Lung 2008;37:72-5.

[11] Katz DE, Lindfield KC, Steenbergen JN, Benziger DP, Blackerby KJ, Knapp AG, et al. A pilot study of high-dose short duration daptomycin for the treatment of patients with complicated skin and skin structure infections caused by Grampositive bacteria. Int J Clin Pract 2008;62:1455-64.

[12] Moise PA, Hershberger E, Amodio-Groton MI, Lamp KC. Safety and clinical outcomes when utilizing high-dose ( $\geq 8 \mathrm{mg} / \mathrm{kg}$ ) daptomycin therapy. Ann Pharmacother 2009;43:1211-9.

[13] Figueroa DA, Mangini E, Amodio-Groton M, Vardianos B, Melchert A, Fana C, et al. Safety of high-dose intravenous daptomycin treatment: three-year cumulative experience in a clinical program. Clin Infect Dis 2009;49:177-80.

[14] Murillo O, Garrigós C, Pachón ME, Euba G, Verdaguer R, Cabellos C, et al. Efficacy of high doses of daptomycin versus alternative therapies against experimental foreign-body infection by methicillin-resistant Staphylococcus aureus. Antimicrob Agents Chemother 2009;53:4252-7. 
[15] Department of Health and Human Services. Cancer therapy evaluation program, common terminology criteria for adverse events, v.3.0. DHHS; 2006. http://ctep.cancer.gov/protocolDevelopment/electronic_applications/docs/ctcaev3. pdf [accessed 28 May 2009]. 
Fig. 1. Creatine phosphokinase (CPK) levels observed in the standard dose (SD) and higher dose (HD) daptomycin groups at different times. The lower and higher edges of the boxes correspond to the 25th and 75th percentiles, respectively; the bars from the sides of the box extend to the 10th and 90th percentiles. 


\section{Table 1}

Characteristics, types of infection, type of Staphylococcus aureus and duration of therapy for study patients in the daptomycin standard dose (SD) and higher dose (HD) groups

\begin{tabular}{|c|c|c|c|}
\hline Characteristic & $\begin{array}{l}\text { SD group }(N \\
=22)\end{array}$ & $\begin{array}{l}\text { HD group }(N \\
=31)\end{array}$ & $\begin{array}{l}P \text { - } \\
\text { value }\end{array}$ \\
\hline Age (years) [median (10-90th percentile)] & $\begin{array}{l}64.5(49.8- \\
79)\end{array}$ & $\begin{array}{l}68(39.4- \\
80.8)\end{array}$ & $\mathrm{N} / \mathrm{S}$ \\
\hline Gender male $[n(\%)]$ & $14(64)$ & $24(77)$ & $\mathrm{N} / \mathrm{S}$ \\
\hline $\begin{array}{l}\text { Duration of hospitalisation (days) [median } \\
\text { (10-90th percentile)] }\end{array}$ & $\begin{array}{l}15(8.3- \\
54.4)\end{array}$ & $23(11-32)$ & $<0.01$ \\
\hline $\begin{array}{l}\text { APACHE II score [median (10-90th } \\
\text { percentile)] }\end{array}$ & $\begin{array}{l}12(7.3- \\
22.4)\end{array}$ & $16(9-21.8)$ & 0.03 \\
\hline \multicolumn{4}{|l|}{ Underlying conditions [n (\%)] } \\
\hline Diabetes mellitus & $3(14)$ & $5(16)$ & $\mathrm{N} / \mathrm{S}$ \\
\hline Peripheral vascular disease & $3(14)$ & $6(19)$ & $\mathrm{N} / \mathrm{S}$ \\
\hline Immunocompromised & $2(9.1)$ & $5(16)$ & $\mathrm{N} / \mathrm{S}$ \\
\hline Neutropenia & $1(4.5)$ & $3(10)$ & $\mathrm{N} / \mathrm{S}$ \\
\hline \multicolumn{4}{|l|}{ Type of infection $[n(\%)]$} \\
\hline Uncomplicated BSI & $10(45)$ & $7(23)$ & $\mathrm{N} / \mathrm{S}$ \\
\hline Complicated BSI & $3(14)$ & $8(26)$ & $\mathrm{N} / \mathrm{S}$ \\
\hline cSSTI & $3(14)$ & $5(16)$ & $\mathrm{N} / \mathrm{S}$ \\
\hline Left-sided endocarditis & $2(9.1)$ & $4(13)$ & $\mathrm{N} / \mathrm{S}$ \\
\hline Right-sided endocarditis & $2(9.1)$ & $5(16)$ & $\mathrm{N} / \mathrm{S}$ \\
\hline Osteomyelitis & $2(9.1)$ & $2(6.5)$ & $\mathrm{N} / \mathrm{S}$ \\
\hline \multicolumn{4}{|l|}{ Type of $S$. aureus $[n(\%)]$} \\
\hline MRSA & $19(86)$ & $27(87)$ & \\
\hline MSSA & $3(14)$ & $4(13)$ & $\mathrm{N} / \mathrm{S}$ \\
\hline $\begin{array}{l}\text { Duration of therapy (days) [median (10-90th } \\
\text { percentile)] }\end{array}$ & $\begin{array}{l}13.5(10- \\
51.3)\end{array}$ & $19(14-52.2)$ & 0.02 \\
\hline
\end{tabular}


N/S, not significant $(P \geq 0.05)$; APACHE, Acute Physiology and Chronic Health Evaluation; BSI, bloodstream infection; cSSTI, complicated skin and soft-tissue infection; MRSA, meticillin-resistant S. aureus MSSA, meticillin-sensitive S. aureus. 


\section{Table 2}

Clinical and microbiological outcomes of higher dose (HD) and standard dose (SD) daptomycin

\begin{tabular}{llll}
\hline & Daptomycin SD & Daptomycin HD & $P$-value \\
\hline Clinical success $[n / N(\%)]$ & $16 / 22(73)$ & $29 / 31(94)$ & 0.05 \\
Uncomplicated BSI & $9 / 10$ & $7 / 7$ & $\mathrm{~N} / \mathrm{S}$ \\
Complicated BSI & $2 / 3$ & $7 / 8$ & $\mathrm{~N} / \mathrm{S}$ \\
cSSTI & $2 / 3$ & $5 / 5$ & $\mathrm{~N} / \mathrm{S}$ \\
Left-sided endocarditis & $1 / 2$ & $3 / 4$ & $\mathrm{~N} / \mathrm{S}$ \\
Right-sided endocarditis & $1 / 2$ & $5 / 5$ & $\mathrm{~N} / \mathrm{S}$ \\
Osteomyelitis & $1 / 2$ & $2 / 2$ & $\mathrm{~N} / \mathrm{S}$ \\
Microbiological success $[n / \mathrm{N}(\%)]$ & $13 / 19(68)$ & $27 / 29(93)$ & $<0.05$ \\
Uncomplicated BSI & $6 / 8$ & $5 / 5$ & $\mathrm{~N} / \mathrm{S}$ \\
Complicated BSI & $2 / 3$ & $7 / 8$ & $\mathrm{~N} / \mathrm{S}$ \\
cSSTI & $2 / 2$ & $5 / 5$ & $\mathrm{~N} / \mathrm{S}$ \\
Left-sided endocarditis & $1 / 2$ & $3 / 4$ & $\mathrm{~N} / \mathrm{S}$ \\
Right-sided endocarditis & $1 / 2$ & $5 / 5$ & $\mathrm{~N} / \mathrm{S}$ \\
Osteomyelitis & $1 / 2$ & $2 / 2$ & $\mathrm{~N} / \mathrm{S}$
\end{tabular}

BSI, bloodstream infection; N/S, not significant $(P \geq 0.05)$; cSSTI, complicated skin and soft-tissue infection. 


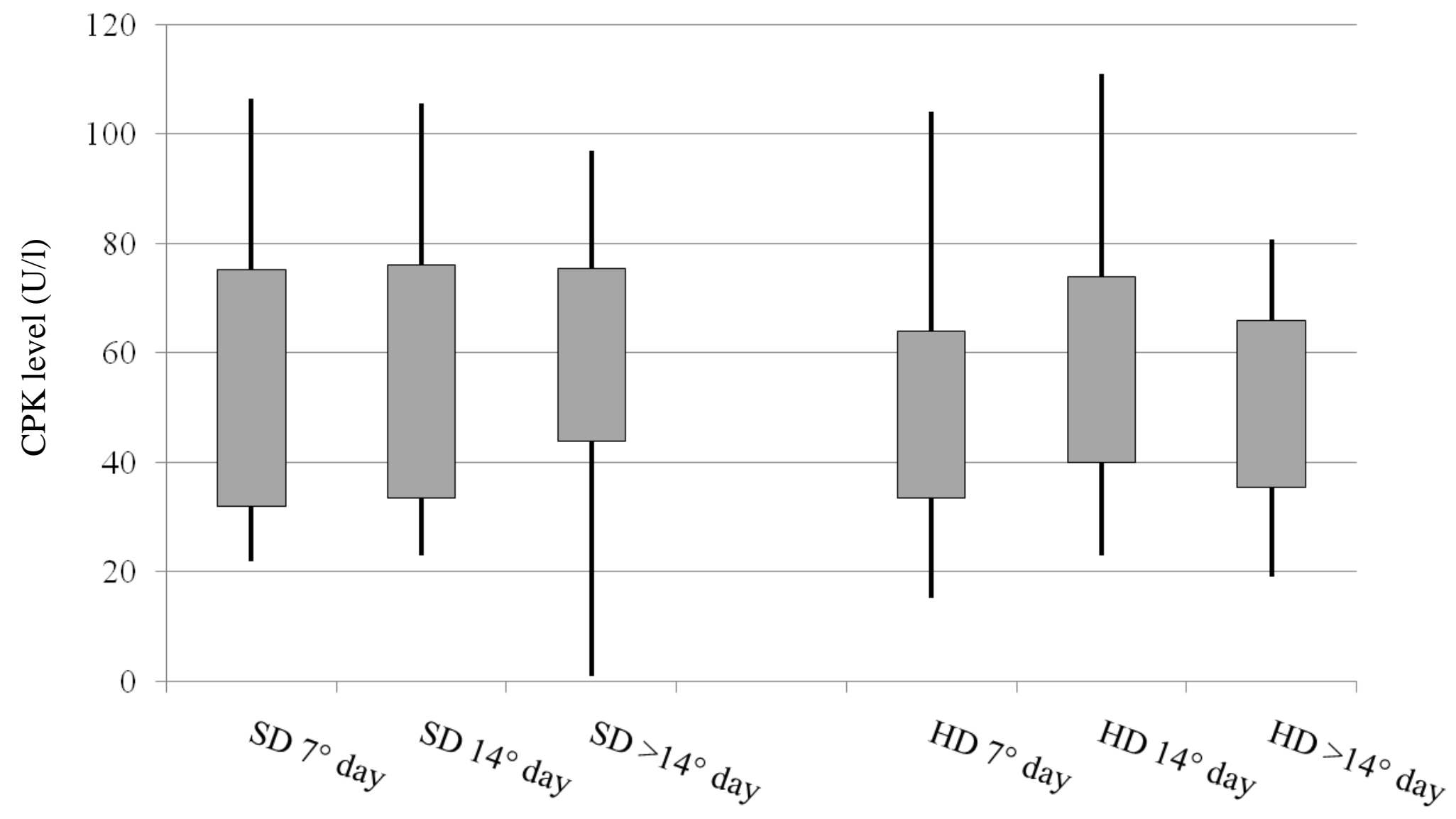

